\title{
Het caleidoscopische Westen
}

\author{
Nanna Verhoeff
}

De western was een actualiteitsgenre. Dat blijkt als we kijken naar films over het Amerikaanse Westen van vóór de (klassieke) western, gemaakt tussen ongeveer I895 en I905. Het meest kenmerkende van deze films zijn de mogelijkheden van het nieuwe medium in combinatie met het specifieke moment in de geschiedenis. $O p$ het kruispunt van medium en moment ervaren we iets, dat hier wordt aangeduid als 'getuige zijn van het verleden.' Dat is een belangrijke ervaring, omdat in de overgang van heden naar verleden de mythe ontstaat. Dat proces, niet het resultaat, heeft ons iets te leren. 'Het Westen', inmiddels een mythe, kunnen we soms nog waarnemen bij zijn ontstaan: voór het eenheidsbeeld dat de mythe later creëert. Over zo'n momentopname gaat deze bijdrage. Want film als medium speelt met ingeblikte actualiteit. Zo zijn de filmische actualiteiten zowel een filmische vorm als een culturele vorm. Toeschouwers worden aangesproken als tijden plaatsgenoten van een uniek moment in de geschiedenis: de verwording van heden tot (mythisch) verleden.

Het lijkt zo'n tegenstelling: films over het avontuurlijke in het Wilde Westen in het kader van moderniteit. Maar het filmische discours waarbinnen de vroege non-fictie films over het Westen vallen, speelt in op, en geeft vorm en beeld aan, dit specifieke cultuurhistorische moment. Dit moment wil ik op twee niveaus bekijken. Ten eerste gaat het hier om de verbeelding en betekenisgeving van het heden en verleden (en het spanningsveld hiertussen) van een cultuur op een bepaald historisch moment. Dit niveau gaat dus over de relatie tussen films over het Westen en de cultuurhistorische context. Het andere niveau houdt de ontwikkeling en verspreiding van het nieuwe technologische massamedium in, om kort te zeggen: de vroege actualiteits-'westerns' in hun specifiek filmische context.

Op I April rgor trok het gezelschap van Buffalo Bill de stad New York binnen. Het was een grote optocht, en het spektakel bracht hele volksstammen op de been. Een eeuw later kunnen we getuige zijn van dit evenement, dankzij de film buffalo bill's wild west parade van de American Mutoscope and Biograph Company (АМ\&B) uit 1902. In dit artikel wil ik aan de hand van dit voorbeeld en andere vroege 'westerns' overdenken wat dat betekent, getuige te zijn van het verleden. 
Op de oude zwart-wit beelden die in het filmarchief liggen zien we een wirwar van mensen, alle in grote opwinding. Het is een tamelijk verwarde beeldenreeks. De eerste seconden is het zelfs moeilijk te onderscheiden wie bij het publiek en wie bij Buffalo Bill hoort.' De mensen in de straten lopen massaal mee met de figuren uit de show die te paard in een stoet door het beeld lopen. Het lijkt moeilijk om je een weg te banen door de massa. Als helden uit het Wilde Westen worden de cowboys, Indianen, soldaten van de cavalerie, en de Rough Riders onthaald in de oostelijke metropool. ${ }^{2}$ De cameraman staat in het midden van deze drukte en registreert de feestelijke happening.

Drie jaar eerder werden er van een zelfde gebeurtenis al films gemaakt door de Edison Company. In parade of buffalo bill's Wild West sHow I en 2, twee films van ongeveer een enkele minuut lang, wordt de optocht getoond. In deze twee korte films uit 1898 zien de beelden er een stuk rustiger uit. De mensen staan aan de kant van de weg en de camera staat tussen de mensen. In de eerste film ziet de straat er uit als een ongeplaveide weg, zoals in een dorp, maar uit de tweede film blijkt het een straat in een grotere stad te zijn waar je aan de elektriciteitsdraden kunt zien dat er trams rondrijden. Het verschil tussen beide filmpjes wijst naar een steeds verschuivende actualiteit. Getuige zijn van het verleden vereist een vorm van inzoomen op dat actualiteitskarakter. Dit brengt me nu eerst naar het filmhistorische moment.

\section{De attractie van actualiteit}

Inderdaad, de attractie van deze korte films was die van hun actualiteit. Een show, die binnenkort in de stad verwacht wordt, wordt alvast aangekondigd in de films: een zakelijke, journalistieke presentatie van een locale en actuele gebeurtenis in een cinematografisch jasje. Mensen die deze films van Buffalo Bill's gezelschap zagen beleefden hem 'in de tegenwoordige tijd'. Bovendien speelt hier het locale karakter van het getoonde een cruciale rol. Toeschouwers wisten dat ze aangesproken werden als tijd- en plaatsgenoten die graag op de hoogte werden gehouden. Deze films als publiekstrekkers spreken de toeschouwers op indringende wijze aan.

De optocht zien we door de ogen van de cameravoerder, die tussen de andere toeschouwers aan de zijkant van de weg staat. De filmkijker staat hierdoor zelf in de actualiteit van het vertoonde, als toeschouwer tussen de ooggetuigen. Maar tegelijkertijd is dit publiek aan de kant van de weg een eventueel toekomstig publiek voor de shows die binnenkort door Buffalo Bill en zijn groep opgevoerd zullen worden in de stad. Ook het toekomstige bioscooppubliek kan zich herkennen in deze mensen, die in de beelden van de film kijken naar de parade. De parade is een smaakmaker. Ooggetuigen 
- het publiek aan de kant van de weg - en bioscoopbezoekers: deze verschillende toeschouwersposities geven aan, dat ook in zulke korte films complexe lagen van representatie aan de orde zijn. Net zo complex is de betekenis van de actualiteit, hier: van het Westen. Het eerste, de toeschouwerspositie, geeft een ingang voor begrip van het tweede, de actualiteit. Laten we dus eerst kijken naar de gelaagde representatie. Vooralsnog is niet direct duidelijk aan te geven wat deze representatie toont, wanneer, en aan wie.

New York, 190I. De straten, de mensen, de opwinding. De showmen, de toeschouwers. De eerste laag van de representatie bestaat uit wat zich voor de camera, in de straten van New York afspeelt: de actualiteit. Deze toont het spektakel van de optocht zelf, met alles eromheen. De parade is een soort reclame. Hij toont niet alleen iets dat in de actualiteit gebeurt - de opwinding -, maar doet dit tevens ten behoeve van iets dat gaat gebeuren, morgen, of vanmiddag. De representatie van de stoet mensen in de film verwijst naar de show die nog komen gaat. Maar de show op zijn beurt is een representatie. De show 'gaat over' iets en dat is - een derde, meer symbolische laag - het 'verhaal' dat de show vertelt. Dat verhaal is een soort autobiografie van mythische proportie. Buffalo Bill heeft zijn eigen leven, zijn eigen verleden tot spektakel gemaakt.

De registratie van deze aankondiging van een show over het verleden wordt vervolgens een spektakel op zich, als onderwerp voor een film die gemaakt wordt om vertoond te worden aan een betalend publiek. De camera maakt de gebeurtenis: verheft het alledaagse gebeuren tot Gebeurtenis. Het richten van de camera op een object, maakt dit tot - significant beeld. Daarmee maakt het een op zich lokaal en voorbijgaand iets tot een aanwijsbaar punt in het verloop van de tijd. In deze gelaagdheid van het beeld is de camera de spil die het moment creëert, vastlegt, en reproduceert.

De complexe representatie specificeert de wijze waarop de films die ik hier beschrijf cultuurhistorische betekenis produceren. Als we ze vergelijken met de hedendaagse nieuwsbulletins op de televisie, dan is het verschil in culturele beleving van 'nieuws' enorm. In plaats van thuis, in de privé-sfeer, geïsoleerd, wordt de actualiteit nog beleefd op straat, of op het kermisterrein waar de nieuwe bewegende beelden vertoond worden voor grote groepen publiek. Deze films zijn representatief voor de actualiteitsfilm die in de eerste jaren van de film populair was. ${ }^{3}$ De actualiteitsfilms waren enerzijds een vorm van journalistiek: vertoond werd, wat er op dat moment, in het heden speelde. Dat was op zich sensationeel nieuws. Anderzijds was het filmische kader deel van de attractie en benadrukte de actualiteit de nieuwe mogelijkheden van het medium om het openbare leven, en dus ook zichzelf, aan het grote publiek te tonen. ${ }^{4}$ Zo trok de optocht van Buffalo Bill het publiek voor een tweede keer. Deze dubbele functie van het actuele als commercieel vermaak is een typerende eigenschap van het nieuwe medium film waar filmmakers zich in de 
eerste jaren van de film op toelegden. Ik wil hier dan ook niet zozeer de nieuwswaarde van deze films benadrukken, als eerder het fenomeen dat de filmische actualiteiten op zich een vorm van amusement zijn. Daarbij hanteert de wijze van verbeelden van het heden-en-verleden eigen representatieve normen. Dit gebeurde in een tijd dat film zelf nog een nieuw verschijnsel was.

Het bijzondere van deze actualiteitsfilms zit in de sensatie van het bijna samenvallen van heden en verleden. De populariteit van non-fictie films die de actuele werkelijkheid van de toeschouwers presenteerden door middel van de filmcamera, waren een uiting van fascinatie met de mogelijkheden van dit nieuwe medium om het heden in een dynamisch beeld te kunnen vatten. Zo kon film de toeschouwer een gevoel van aanwezigheid geven.' Sinds de televisie vinden we dat heel gewoon, en worden er steeds nieuwere en extremere vormen van aanwezigheid en interactiviteit bedacht door programmamakers. Honderd jaar geleden was dit een wonderbaarlijk fenomeen. Niet alleen de bewegende beelden waren nieuw, maar helemaal spectaculair was de kans zichzelf te herkennen op het scherm.

Waar komt deze fascinatie vandaan en welke rol krijgt deze in de culturele plaats van de film? Natuurlijk speelt de technologische achtergrond mee: de experimenten met fotografie van Eadwaerd Muybridge, de chronofotografie van Etienne-Jules Marey als voorloper van de filmcamera, of de snelle verspreiding van geilllustreerde kranten en tijdschriften in de loop van de negentiende eeuw; dit zijn allemaal symptomen van de preoccupatie met de actualiteit. 'Echt' getuige kunnen zijn door te kijken naar films waarvan men de actualiteit ook nog zelf had meegemaakt, was het toppunt van temporele authenticiteit. ${ }^{6}$ Deze fascinatie domineerde de eerste tien jaar van de filmproductie en inspireerde de creatie van de specifieke representatievormen van dit eerste filmgenre. Ik wil hier niet teveel ingaan op het bredere discours van actualiteit en authenticiteit aan het eind van de negentiende eeuw en de bijbehorende technologieën, waarbinnen film zijn eigen rol speelt. ${ }^{7}$ Het gaat mij hier om de uitbeelding van het Westen in die tijd, omdat het Westen op het punt van verdwijnen, getuigenis aflegt van het ontstaan van mythen als overgang van heden naar verleden.

De allereerste films die werden opgenomen dienden als illustratie voor de uitvinding zelf, maar tegelijkertijd worden de relatie tussen medium en omgeving en de ambities van de producenten duidelijk. In eerste instantie werd de directe omgeving van de uitvinders hiervoor als onderwerp genomen. ${ }^{8}$ Vrijwel meteen nodigde Edison mensen uit die in de publieke belangstelling stonden, of mensen die iets te vertonen hadden wat publiek trok, zoals boksers, acteurs of rodeosterren, om in de studio hun kunsten te vertonen. $\mathrm{Al}$ snel werden actuele gebeurtenissen of exotische locaties onderwerp voor de camera. Illustratie van de technologie wordt dus ook illustratie van het medium: wat het kan, doet, en maakt. 
De camera ging letterlijk en figuurlijk naar buiten om het leven in alle vormen op te nemen. De gretigheid om te registreren wat de moeite waard was, bepaalde wát de moeite waard werd gevonden. Voor de vertoningen van deze films werd een aantal korte films samengevoegd tot een avondvullend programma, al dan niet afgewisseld door variété en muziek. De variëteit aan beelden werd enerzijds bijeengehouden door deze context van het totale programma. Anderzijds benadrukte juist de programmavorm de fragmentatie. Het hier eerst genoemde mechanisme, de beeldenvariëteit, betreft de wijze waarop film een rol speelt in de productie en circulatie van visies op het heden en verleden rond de eeuwwisseling. Kortom, ik ga nu na waar de culturele betekenis van de actualiteitsfilm vandaan komt en wat voor rol de verbeelding van het Amerikaanse Westen speelt. Dit brengt me tot het cultuurhistorische moment.

\section{Instant nostalgie}

De films over Buffalo Bill's Wild West brengen het Amerikaanse Westen naar het stedelijke Oosten in dit kader van de actualiteit-als-amusement. Wat is de verklaring voor de populariteit van films over het Westen met deze actualiteitslaag? Waarom is bij uitstek het non-fictie genre van actualiteiten geschikt voor de registratie van een verdwijnend heden, of liever gezegd, van de glijdende overgang van het recente verleden naar een mythisch en symbolisch verleden? Hiervoor is een samenloop van omstandigheden als verklaring te geven. De gelijktijdigheid van het verdwijnen van het Wilde Westen, het ontstaan van een mythe over dit verleden, en het begin van het typisch moderne massamedium film, scheppen samen de voorwaarden voor deze populariteit.

In 1890 werd de frontier, de steeds verder oprukkende scheidslijn tussen 'wildernis' en 'beschaving' van de westwaartse expansie van de Verenigde Staten, tot gesloten verklaard. Op het moment waarover ik het hier heb, 190I-1902, was dit dus nog maar net gebeurd. De bevolkingsdichtheid in de westelijke regionen van de Verenigde Staten was zo gegroeid dat van het Wilde Westen niet meer gesproken kon worden. Terwijl deze veranderingen nog vers in het geheugen lagen, trad Buffalo Bill op als een incarnatie van wat zojuist nog had bestaan, maar nu onherroepelijk verloren was. Symbolisch voor deze coïncidentie is de aanwezigheid van Buffalo Bill's show op de World's Columbian Exposition in Chicago in 1893. Daar hield toen ook Frederick Jackson Turner zijn beroemde lezing 'The Significance of the Frontier in American History' voor de leden van de American Historical Association. Naar aanleiding van de officiële sluiting van de frontier in 1890 - op basis van bevolkingsdichtheid, gemeten door het Census Bureau -, legt 


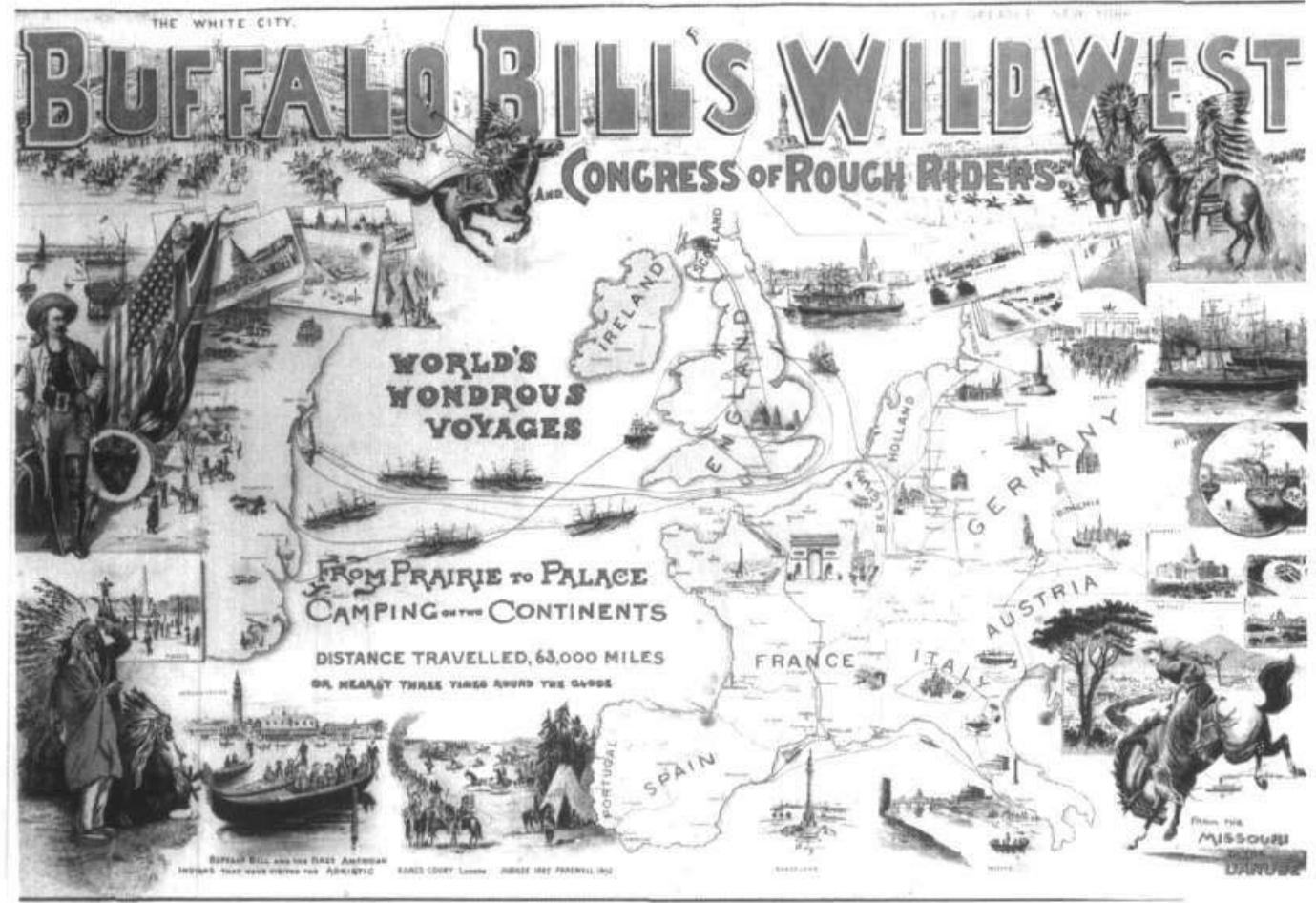

Poster van Buffalo Bill's Wild West and Congress of Rough Riders: "World's Wondrous Voyages", kleurenposter, c. 1892 , anoniem Bron: Myth of the West met introductie van Chris Bruce. Henry Art Gallery en University of Washington, Seattle, 1990 p.140.

134
Turner het belang van de verschuivende grens van de westwaartse expansie voor het verloop van Amerikaanse geschiedenis uit.

Beide mannen, de één historicus, de ander showman, verklaarden ieder op hun eigen manier het belang van het verleden van het Westen op het cruciale moment van het verdwijnen van (deze vorm van) dit verleden. Frappant is dat Edison tevens van plan was om op deze expositie in Chicago zijn uitvinding van de kinetoscoop te demonstreren, wat door vertraging in het productieproces niet kon doorgaan.'

De verklaring voor de oplevende belangstelling voor het Westen, juist op het moment van zijn verdwijning - die Buffalo Bill's shows suggereren was, anders dan die van de historicus, een visuele en (semi)fictionele. Daardoor sprak hij rechtstreeks en op grote schaal tot de culturele verbeelding. Hij toonde én memoreerde tegelijkertijd het heden en het verleden. Door zijn eigen verleden tot show te maken, werd Buffalo Bill hét voorbeeld van de mythologisering van het nog maar net verdwenen Wilde Westen. Actualiteit en onherroepelijk verloren verleden smolten samen.

Zo kon dat pas verdwenen verleden object van verlangen worden. Het nieuwe medium maakte het vervolgens mogelijk, het verleden nogmaals op te voeren. Deze herhaling creëerde zo een verlenging van het verleden, en maakte deze 'actuele verleden tijd' beschikbaar voor glorificatie en mythe- 
vorming. ${ }^{10}$ Hiermee deden deze films een welhaast onweerstaanbaar beroep op een nieuw levensgevoel, kenmerkend voor het moderne stedelijke twintigste-eeuwse leven. Deze nostalgie ondersteunde het heden, het moderne levensgevoel, door dat te voorzien van een nog gevoeld verleden. Dit levensgevoel werd rond de eeuwwisseling bepaald door een enorme versnelling in modernisatie door industrialisatie, een geweldige stedengroei, en de grootste migratiegolf die Amerika gekend heeft. Juist dit versnellingsproces lokte een verlangen naar conservering uit. Deze directe en ingeblikte vorm van vasthouden van wat men begint te missen, voldoet op dat historische moment aan een behoefte, die ik instant nostalgie noem.

Deze instant nostalgie is in dit geval een culturele behoefte. Die kwam op in een tijd van crisis en overgang, wat een verlangen teweegbracht om directe getuige te zijn van de geschiedenis. Niet een treurend verlangen naar het afgesloten verleden staat centraal, maar een meer optimistische vorm van koestering van het verleden als nog aanwezig in het heden; een zoete nostalgie. Deze wordt gevoed door het verlangen om de sporen van het verleden nog in het heden aan te kunnen treffen. Het gaat om méér dan het vasthouden van het verleden. Men had grote behoefte aan de mogelijkheden om het verleden opnieuw op te kunnen voeren als een zich herhalende levenscyclus. De cadans van zo'n mogelijke herhaling is geruststellend in een tijd waarin overzicht over de toekomst ontbreekt. Die onduidelijke toekomst was wel opwindend, maar ook beangstigend. De actualisering van het verleden is dan ook paradoxaal. De 'aanwezigheid' van het verleden op het moment van het verdwijnen ervan biedt de mogelijkheid om zowel het vergankelijke als het blijvende te benadrukken.

Hierbij wil ik het instant-karakter van deze beleving benadrukken: de directe behoefte om op de korte termijn een proces van verdwijnen stop te zetten door juist dit moment van overgang te herhalen. Daarin is nostalgie een sentiment van grote collectieve betekenis. Het doet een beroep op persoonlijk gevoel, maar ook op collectiviteit." Deze dubbele aard van nostalgie maakt het sentiment zo bijzonder geschikt voor deze mythevorming in progress van het nationale verleden van de ontginning van het Westen. Voor de zich ontwikkelende rol van massamedia als collectief amusement in dit proces is deze persoonlijke investering van de actuele kijker van destijds door diens nostalgie van cruciaal belang. We zullen zien dat, hoe paradoxaal dit ook klinkt, de actualiteitsfilm als niet-fictioneel genre bij uitstek geschikt was om die nostalgie te voeden.

Op welke wijze nu werpen de non-fictie films over het Westen een licht op de complexe relatie tussen het moderne heden en het nostalgische verleden? De hiervóór besproken actualiteitsfilms van parades zijn maar enkele voorbeelden van non-fictie filmvormen tijdens deze eerste jaren van het medium, die gebaseerd zijn op een instant nostalgie. In dezelfde tijd 
Filmframe vans BUCKING BRONCHO

(Edison, 1894)

Bron: Website van de Library of Congress (http://memory. loc.gov/ammem/) werden ook meer directe vormen van spektakel, zoals vaudeville of andere shownummers geregistreerd. Ook in deze vorm deed het Wilde Westen het bijzonder goed. De Edison Manufacturing Company, dezelfde maatschappij die de PARADE OF BUfFAlO BILl's WILD WEST SHOW in 1898 filmde, nam gedurende de herfst van 1894 een serie films op toen de Show een bezoek bracht aan New York. Deze keer waren het geen opnamen van het bezoek aan de stad, maar registraties van showelementen die speciaal voor de camera werden (her)vertoond. De actualiteit stond minder centraal; de stunts, kostuums, en de helden van de show des te meer. Zoals Alison Griffiths schrijft: "The modular form of the Wild West Show, which combined elements of the circus, the parade, the carnival, the stage spectacular, and the melodrama into a single spectacular event, made it particularly amenable to cinematic translation, perhaps one of the reasons Edison invited such celebrities as Annie Oakley, Eugene Sandow, and Anabelle Whitford to perform in front of his new kinetoscope." ${ }^{12}$ Toch werd in de advertenties en krantenberichten benadrukt dat het recente bezoek van de groep aan de stad de aanleiding was voor de opnamen, en de bezoeken aan de Edison studio in New Jersey werden uitgebreid beschreven. ${ }^{13}$ De actualiteit van het gefilmde werd hier meer benadrukt dan de noviteit van het medium, of liever gezegd, de actualiteit van de films benadrukte de attractie van het medium als doorgeefluik van spektakel zoals dat van de Wild West Show.

Uit de titels van de kinetoscoopfilms die bij dit bezoek aan Edisons studio zijn opgenomen is de populariteit en de filmische aantrekkelijkheid van het westen op te maken. Neem bijvoorbeeld: BUfFALO BILL, sioux GHOST DANCE, BUFFALO DANCE, INDIAN WAR COUNCIL, A BUCKING BRONCHO, en ANNIE OAKLEY. . $^{14}$

In A BUCKING BRONCHO is een buitenopname te zien van rodeo-ster Lee Martin. In de Edison catalogus wordt de film beschreven als: 'A fine exhibition of horsemanship by Lee Martin, a genuine cowboy. This particular broncho is an unusually wicked one.' ${ }^{\text {'s }}$ Let op het woord 'genuine' dat het realistische en actuele benadrukt.

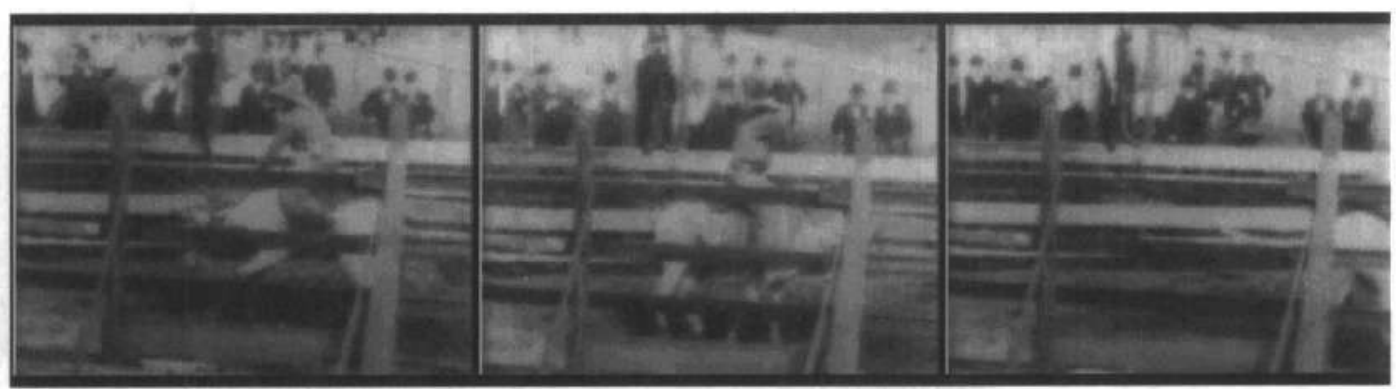



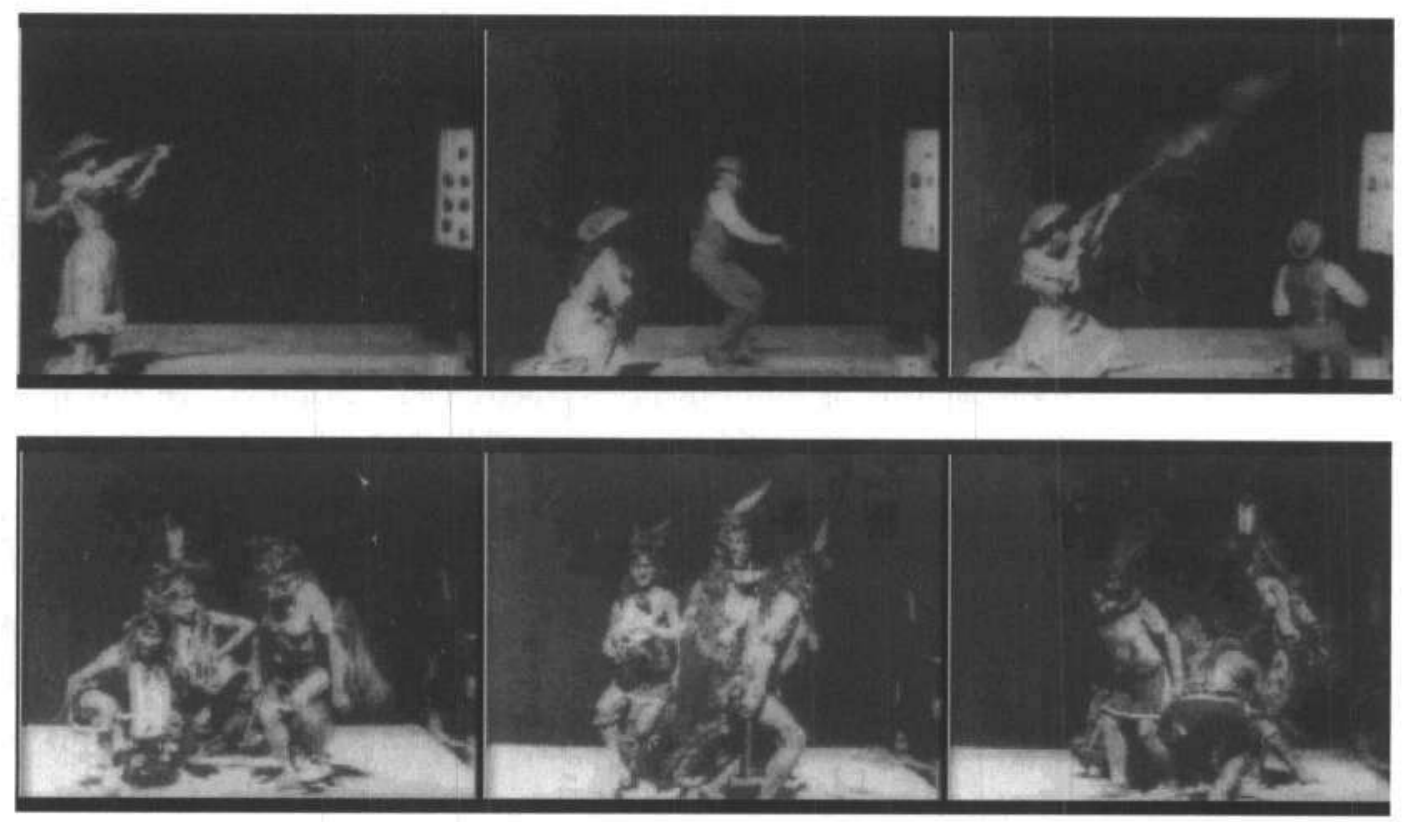

Annie Oakley toont haar schietkunsten voor de camera tegen de zwarte achtergrond van het podium in Edisons studio. Een assistent werpt schijven in de lucht die zij efficiënt in diggelen schiet.

Op hetzelfde podium zijn in de films SIOUX GHOST DANCE en BUFFALO DANCE Indianen uit de groep van Buffalo Bill te zien die in kostuums 'traditionele' dansen voor de camera opvoeren. De dansers kijken naar de toeschouwer en doorbreken zo het etnografische kader, en benadrukken in de plaats daarvan het performatieve karakter van hun act. Ook hier zien we een complexe representatie, benadrukt door de uitbeelding van het kijken zelf, hier zelfs in de vorm van een geretourneerde blik.

Deze films zijn gebaseerd op een vrij directe vorm van (re)presentatie. Toch verwijzen ze naar de complexe lagen van representatie die ik heb genoemd in het geval van de parade films. De acts van de show werden zelf geregistreerd voor de filmtoeschouwer, maar deze films fungeerden tevens als een aankondiging ervan. Zoals Charles Musser concludeert: 'With the kinetoscope [...] performers and amusement entrepreneurs quickly concluded that moving pictures were good publicity and could help their careers. ${ }^{16}$ Het commerciële doel van zowel de filmmakers als de showmensen werd dus gediend, iets wat de positie van het jonge medium plaatst in het kader van de oudere amusementstradities ten behoeve van een jong sentiment.

Naast de genres die bloeiden dankzij de verbondenheid van het jonge medium met de wereld van het theater en vaudeville en de conventies van representatie die werden overgenomen voor de filmische presentatie van de

Filmframe van ANNIE OAKLEY (Edison, 1894) en

BUFFALO DANCE (Edison, 1894) Bron: Website van de Library of Congress (http://memory.loc. gov/ammem/) 
acts, verschenen in deze periode ook andere filmische non-fictie genres die geschikt bleken voor de verbeelding van het Westen. De hierboven beschreven films van Buffalo Bill's Wild West parade zijn gerelateerd aan de films die show- en theaterelementen tonen, zoals de besproken vaudeville- of rodeonummers. Ze vallen tevens onder een ander genre dat ik hier voor het gemak paradefilms noem. Deze films hebben een sterk militaristische en nationalistische inslag en de aanwezigheid van een flink aantal films met western-figuren is opvallend. Deze context van militaire parades en optochten van andere nationalistische gezelschappen benadrukt vergelijkbare eigenschappen van de wildwest parade van Buffalo Bill. ${ }^{17}$

Korte films van reizen naar het Westen (COACHES GOING To CINNABAR FROM YELLOWSTONE PARK, [studio onbekend] I899; TOURISTS GOING ROUND YELLOWSTONE PARK, Edison 1899), en landschapsfilms (CANYON OF THE RIO GRANDE, Edison I898; PANORAMIC VIEW OF MOKI-LAND, Edison 19OI) toonden het landschap en de onherbergzaamheid, dan wel de bereikbaarheid van de westelijke regionen. Films werden getoond waarin het leven van alledag van cowboys en andere westerners werd verbeeld (ROCKING GOLD IN THE KLONDIKE, Edison I9OI; DRIVING cattle to pasture, Edison 1904; ROUNDING UP AND BRANDING CATTLE, Edison I904; A ROUND-UP IN OKLAHомA, Oklahoma Natural Mutoscene 1908). Daarnaast ontstonden etnografische portretten, of gefilmde opvoeringen van ceremoniële dansen van Indianen (INDIAN DAY SCHOOL, Edison I898; WASH DAY IN MEXICO, Edison 1897; WAND DANCE, PUEBLO INDIANS, Edison I898; HOPI INDIANS DANCE FOR THEODORE ROOSEVELT AT WALPI, ARIZONA, [studio onbekend] I913) en gefilmde onderdelen van etnografische tentoonstellingen (ESQUIMAUX VILLAGE, Edison I9OI; ESQUIMAUX GAME OF SNAP-THE-WHIP, Edison 19OI). Deze diversiteit aan beelden van het Westen kon verspreid worden over de vele filmische genres die in de beginjaren van de film de filmprogramma's vulden. Dit brengt me tot de behandeling van het samenvallen van het filmhistorische en het cultuurhistorische moment.

\section{Caleidoscoop}

Dat moment van samenvallen werd gekenmerkt door diversiteit. Deze diverse filmvormen, die vallen onder wat Tom Gunning en André Gaudreault Cinema of Attractions noemen, schetsen een divers, versnipperd beeld van de wereld; een beeld, dat uitgesproken caleidoscopisch is. De Cinema of Attractions is een filmvorm die op een directe manier de aandacht van de toeschouwer vraagt, nieuwsgierigheid opwekt en een visuele bevrediging biedt voor deze nieuwsgierigheid. ${ }^{18}$ Kenmerkend is de manier waarop deze vorm 
niet gebaseerd is op een verhaal, een vertelling, maar op de presentatie en demonstratie van attracties. Gunning benadrukt de esthetiek van de viewals onderdeel van de cinema of attractions. Hierbij beschrijft hij de view als basisvorm voor vroege non-fictie, die gebaseerd is op de presentatie van iets dat vóór de camera een eigen leven heeft. Hiermee onderscheidt hij de view van de cinema of attractions, waarbij hij het presentatieve karakter in de eigen presentatie van de film lokaliseert:

\begin{abstract}
'With this term [view], I mean to highlight the way early actuality films were structured around presenting something visually, capturing and preserving a look or vantage point. In this respect the 'view' clearly forms part of what I have called the 'cinema of attractions', the emphasis found in early cinema upon the act of display and the satisfying of visual curiosity. As an actuality a 'view' makes a greater claim to recoding an event of natural or social history, while attractions include artificially arranged scenes enacted precisely to arouse and sate the spectator's curiosity. ${ }^{\prime \prime}$
\end{abstract}

Hierbij maakt hij dus een onderscheid dat vergelijkbaar is met het verschil tussen de actualiteitsfilms zoals ik hierboven heb beschreven, en de andere filmvormen die gebaseerd zijn op acts die voor de camera zijn opgevoerd. Beide vormen zijn dus onderdeel van de cinema of attractions, maar geven een andere relatie met het gefilmde weer.

Het caleidoscopische beeld is divers, visueel en presentatief in plaats van vertellend, en schetst een exotisch, of bijna toeristisch, beeld van de wereld. ${ }^{20}$ De verbeelding van het Westen laat een veelheid aan verschillende benaderingen zien: het Westen als verleden, als exotische plek, als locatie voor actie en avontuur, of als actualiteit. Uit deze benaderingen blijkt dat de betekenis van het Westen ligt op het kruispunt van tijd en plaats. De verschillende tijdslagen die bij deze visies op de (geografische) plek horen, worden beschreven in vormen die vitaliteit benadrukken. Dit effect komt tot stand zowel door het spektakel van fictie (het tot leven wekken, of opvoeren van, bijvoorbeeld, het leven in het Westen) als door de documentaire beschrijving van non-fictie (het tonen van een levend heden in het Westen).

Eén kant van dit caleidoscopische is van technisch-culturele aard. De films waren erg kort, en werden daarom in combinaties vertoond. Het filmprogramma geeft ruimte aan deze diversiteit van beelden en betekenissen en geeft die tegelijkertijd een samenhang door de gemeenschappelijke nadruk op (visuele) attractie. De wijze waarop thema's uit non-fictie films terugkomen in korte (fictionele) sketches, waarin gespeeld werd met manieren om typische western-gebeurtenissen in een komische of dramatische vorm te gieten, benadrukken de invloed die de korte films in hun effect op elkaar hadden, simpelweg omdat ze achter elkaar werden gezien: 
het contexteffectvan het filmprogramma. In het programma kan makkelijk heen-en-weer geschakeld worden tussen fictie en non-fictie, tussen nieuwsfeiten en historische reconstructies. De verschillende typen films over het Westen konden naast elkaar vertoond worden zonder dat de ene betekenis de andere tegensprak: actualiteit en verleden, fictie en documentatie, alles liep door elkaar. De verschillende betekenissen versterkten elkaar juist op deze manier.

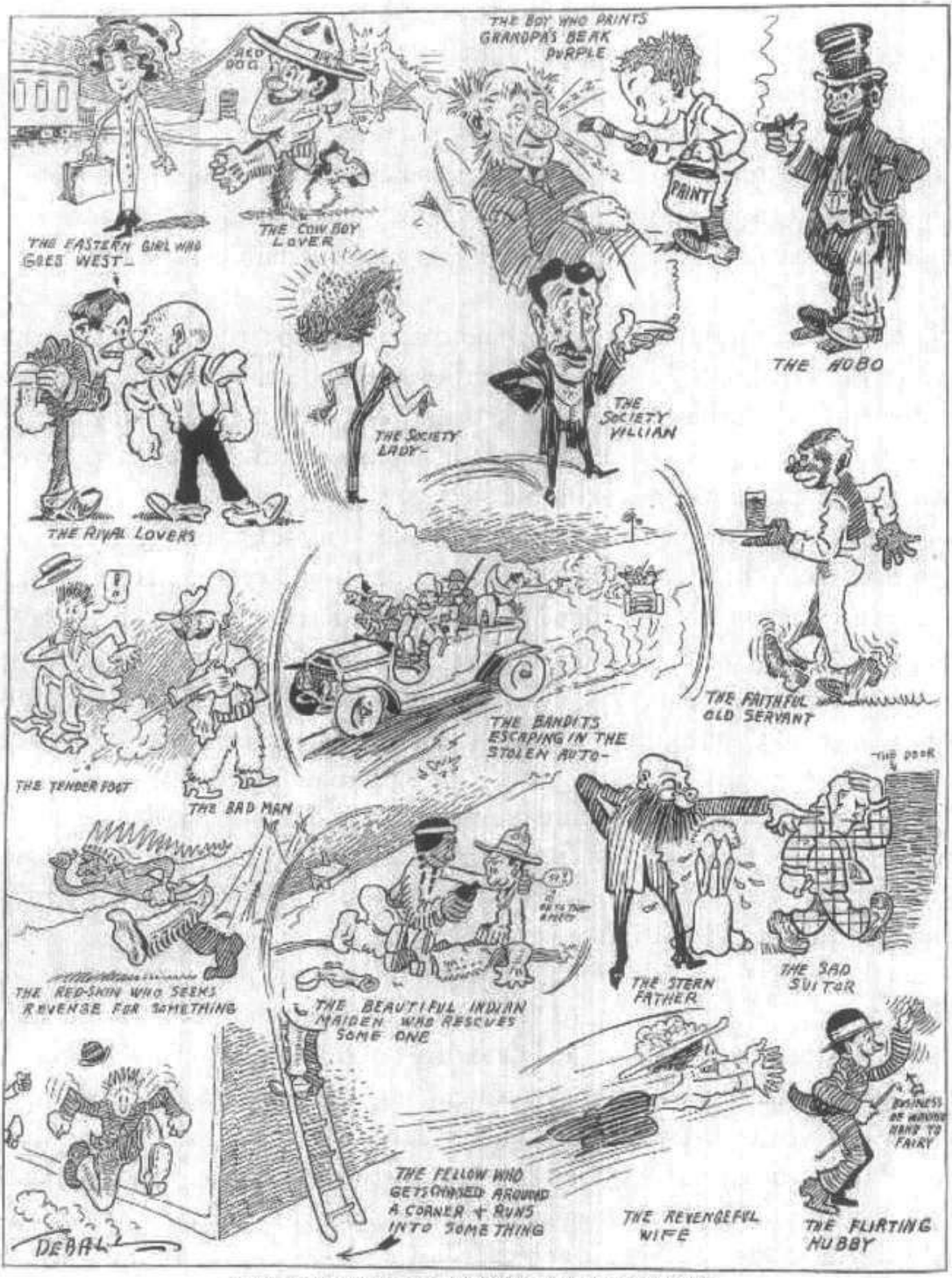

"What would the film producer do without these?" Bevat stereotypes en typische scenes van verschillende genres Bron: Nickelodeon

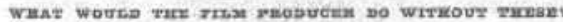


Waarom is nu dat caleidoscopische karakter van de (film)cultuur zo specifiek belangrijk voor de vraag naar de aard van het filmische discours waarbinnen de vroege non-fictie films over het Westen vallen? Met andere woorden, de vraag is hoe dat discours inspeelt op, en vorm en beeld geeft aan, dit specifieke cultuurhistorische moment. De relatie tussen het caleidoscopische karakter van film, met de actualiteitsfilm als ingrediënt daarvan, en instant nostalgie als cultureel sentiment, vraagt dan ook om een nadere blik op de werking van mythevorming en de bijdrage van film daaraan. Juist dit caleidoscopische vormt de mythe van het Westen om tot western. Mythevorming, zo blijkt hier, gaat op die manier in zijn werk: de veelheid aan schakeringen in het geschetste beeld wordt op den duur, in vrij korte tijd, opgenomen in een min of meer afgebakend genre. Daarin werd een caleidoscopische visie geboden, waarin een mythisch 'Westen' ontstond. Mythe en genre gaan dus hand in hand.

Om dit proces van genreformatie weer te geven, is wel de term 'bricolage' voorgesteld. Met de term bricolage, ontleend aan de structuralistische antropoloog Claude Lévi-Strauss, is de tekstuele diversiteit aan te geven van het samengestelde beeld. De term kan gebruikt worden om de veelvormigheid van invloeden op zowel de techniek als de representatiepraktijk van vroege film aan te duiden. ${ }^{22}$ Miriam Hansen benadrukt de openheid van genres in deze periode. Ze geeft aan hoe de individuele films door bricolage verwijzen naar andere films: 'In preserving a stylistic heterogeneity of their component parts they invoke a larger field of bricolage of which the individual film is only a segment, as is the program in which it is shown. ${ }^{23} \mathrm{Ik}$ wil hier gebruik maken van dit begrip om de samenstelling van het caleidoscopische beeld aan te geven, evenals de manier waarop dit een plaats vindt in de ontwikkeling van verschillende genres, maar daarin tevens de mythevorming opnemen. Hier zit overigens nog een kant aan, die ik hier slechts kan noemen: in het geval van de vroege film is dit proces van bricolage ook zichtbaar in de samenstelling van de filmprogramma's die gebaseerd zijn op diversiteit. Dit is van belang, omdat in de loop van de ontwikkeling van langere narratieve films in de periode 1904-1907 en in de ontwikkeling van genres, men gebruik maakte van deze verschillende, reeds in de programma's aanwezige visuele thema's.

Deze vertoningpraktijk is deel van de caleidoscopische cultuur, omdat de 'ontwikkeling' van het genre van de western anders niet begrepen kan worden. Een anekdote kan deze overgang van kortere attracties naar langere narraties illustreren. Ik doel op de verwarring rond de receptie van LIFE оғ А сошвоч (Edison, 1907). Uit de filmbeschrijving in Variety blijkt dat de recensent uitgaat van een film die bestaat uit verschillende, los van elkaar staande scènes, die een caleidoscopisch geheel vormen: 'A long and interesting moving picture is LIFE OF A COW BOy shown at Pastor's. It 
covers a wide range of subjects and the locale seems to be really the Western Plains. ${ }^{24}$ Hierna beschrijft de auteur de reikwijdte van de film in een opsomming van scènes die de diversiteit benadrukt. De bedoeling van de makers was echter een heel andere. Uit de beschrijving van de film die de Edison studio publiceert in Film Index blijkt dat de makers een samenhangend verhaal bedoelden, verteld in scènes die episodes voorstellen uit eén lang avontuur. ${ }^{25}$

De discrepantie tussen intentie en receptie is hoogst betekenisvol voor begrip van de caleidoscopische filmcultuur als fundamenteel anders dan die van de langere westerns. Uit de interpretatie van de recensent blijkt de film in zijn ogen te passen in de traditie van korte films met een nadruk op non-fictie of in ieder geval nagespeelde non-fictie, terwijl de makers poogden een langer narratief te vertellen met de nadruk op een (fictief) avontuur. We zien in deze anekdote precies gebeuren wat ik met dit stuk in algemenere termen probeer te beschrijven: we zijn getuige van een moment waarop de ene tijd, met zijn traditie, vorm, en genre, overgaat in een radicaal andere.

Bricolage en de geschakeerde context van het filmprogramma geven de caleidoscopische samenstelling van het beeld, en daarmee de culturele betekenis van het Westen, vorm binnen de zich volop ontwikkelende filmpraktijk. Dit procédé is bepalend voor de manier waarop het genre van de western zich ontwikkelt en hoe deze eerste fase van filmische representatie (nog) bestaat uit een openheid en diversiteit die later opgenomen wordt in de 'eenheid' van het klassieke genre. Zoals Miriam Hansen schrijft:

'While the classical genre film relies upon the viewer's intertextual awareness primarily within the specialized category of one and the same genre and according to preexisting standards of homogeneity, the films in question mobilize intertextual awareness across genre boundaries, playing with contiguities among formally distinct types of film. ${ }^{126}$

Kort en goed: de caleidoscoop is een filmcultuur. Maar 'cultuur' is meer dan een verzameling films. Cultuur bevat objecten, sentiment, en praktijk, zoals vertoningspraktijk. Het caleidoscopische is in die zin een culturele 'vorm' die bestaat uit korte filmische segmenten, samengevat in de meervoudige vorm van het filmprogramma, waarbij het actualiteitseffect van het recente verleden de instant-nostalgie voedt. Dit brengt me tenslotte tot het heden: welke cultuurhistorische les valt er te trekken uit Buffalo Bill's paradefilms? 


\section{Geschiedenisles}

Wanneer de filmhistoricus Kevin Brownlow schrijft:

'No one goes to a Western for a history lesson, so to charge most Westerns with inaccuracy is pointless. In any case, the history of the West is as plagued by myth as the history of the cinema, and to untwine the barbed wire of legend is all but hopeless',

kan ik hem in eerste instantie niet ongelijk geven. ${ }^{27} \mathrm{Zijn}$ weerlegging van de common-sense opvatting over historische film in het algemeen, en van westerns in het bijzonder, is zeker relevant, echter niet voldoende. Juist in het geval van de western is het een duidelijk argument om te stellen dat het niet in de eerste plaats een vorm van geschiedschrijving is maar - een urgentere behoefte van die tijd - een mythevorming. In die zin is het interessant, hoe de relatie tussen heden en verleden in de loop van de geschiedenis verandert. Dit historische moment van mythevorming verdient een plaats in de filmgeschiedschrijving. Een genre-in-wording als de western avant-la-lettre toont een houding ten opzichte van het verleden maar definieert in feite ook dit verleden.

De rol van de western als constructie van een nationaal verleden is groot; dat weet iedereen. Juist daarom wil ik met deze films over het Westen, vóórdat er sprake is van een monumentaal western genre, de non-fictietraditie in svroege film van actualiteit-als-amusement, verbinden met de specifieke instant-nostalgie op het kruispunt van een enthousiasme voor moderniteit en een nostalgisch terugverlangen naar het recente verleden.

De wijze waarop de culturele betekenis van actualiteiten en instantnostalgie samenkomen in de samenstelling van het caleidoscopische beeld van het Westen in de eerste jaren van de film, maakt niet alleen duidelijk hoe het medium film hiermee een eigen visie op de werkelijkheid verbeeldt. Deze combinatie van actualiteit en nostalgie laat zien hoe de verhouding tussen heden en verleden én tussen feit en fictie dynamisch is en in de loop van de geschiedenis verandert. De betekenis van het Wilde Westen heeft verschillende tijdsdimensies die bij uitstek rond de eeuwwisseling opvallend zijn. Zo was het Westen lang een soort veilige buffer, een reserveland voor de toekomst, een utopisch gebied voor een tijd waarin men dat land nodig zou kunnen hebben. Deze betekenis en dit beeld van het Westen raakten gedateerd. Ze moesten aangepast worden op het moment dat de westwaartse expansie tot een einde kwam. De reactie op deze bijstelling van de toekomstvisie was een retrospectieve mythevorming, met een mix van nostalgie voor het verleden en een utopisch escapisme van het heden, waarbij het beeld van een geografisch Westen een temporeel Westen maakt. Zo kon 
het Westen functioneren met een actualiteit die bij uitstek door film wordt overgedragen. In samenhang met de korte tijd die lag tussen de afsluiting van het verleden en de nostalgische conservering ervan, leende deze vanishing world zich voor een veelvormige presentatie. Film als medium bood de mogelijkheid, die veelheid aan aspecten op te slaan, uit te testen, gelijktijdig aan te bieden. Het medium en de caleidoscopische vorm pasten in die zin voortreffelijk bij elkaar.

De filmcultuur was nog niet 'vormvast'. De genres hadden daarbinnen nog niet de vaste vorm die ze later zouden krijgen. De langzame fixatie waarin de actualiteit plaats maakte voor fictie, ging niet zonder slag of stoot. Zo kwamen er na verloop van tijd klachten over de overgang van non-fictie naar fictie. Een journalist schreef in Moving Picture News.

'The public is getting utterly sick and tired, utterly disgusted with the bad photography, the illogical stories, the poor acting, the general shooting and hold-up, that is being illustrated in these Wild West pictures, and, with the exhibitors, we feel the time has come when some stay should be made in thrusting these subjects before the public. Not only are the Wild West pictures absolutely incongruous, but they offend the better taste of the Western people, the settlers in Western towns. ${ }^{28}$

Geprezen worden films met een actuele documentaire inslag, zoals in het geval van THE LAND OF PROMISE (Imp. I912) waarbij het contemporane van het verhaal het realisme onderstreept:

'The picture gives the opportunity for the portrayal of graphic scenes of Western life to-day - not the Western life of a decade ago, the wild Western life that is rapidly becoming forgotten, but natural incidents associated with the agricul- tural and cattle raising in the far Western states of to-day. ${ }^{, 29}$

In de ontwikkeling van het genre van de western speelt de retoriek van de beschreven caleidoscopische verbeelding een zeer invloedrijke rol. Toch zal uit de filmgeschiedenis alleen al blijken dat in de loop van de jaren, naarmate het Wilde Westen meer en meer tot een mythisch verleden gaat behoren, het genre van de western juist steeds meer de kant op gaat van het vertellen van epische heldenverhalen en de actuele, contemporaine laag van de vroege films verliest. De instant-nostalgie verandert van kleur en de rol van de actualiteit zal verdwijnen naarmate de films meer naar de western dan naar het Westen verwijzen. De parades van Buffalo Bill veranderen zo ook van betekenis, van een onderhoudend nieuwsfeit tot object van nostalgie. Zoals Richard Slotkin concludeert over het einde van Buffalo Bill's shows in I917: 
'[Buffalo Bill's cycle of 'Farewell Performances'] reveal the extent to which the Myth of the Frontier had become independent of the historical reality that produced it. In Cody's farewell tours, that nostalgia for the 'Old West' that had been the basis for his first success gave way to a new form of the sentiment: a nostalgia not for the reality, but for the myth - not for the frontier itself, but for the lost glamour of Buffalo Bill's Wild West. ${ }^{30}$

Van getuigen van het instant verleden zijn we getuigen geworden van de mythe: de actualiteitsfilm is speelfilm geworden, de caleidoscoop is verdwenen en het Westen is 'western' geworden. Dat niet de inhoud van de western een geschiedenisles biedt, maar de veranderende betekenis ervan in zijn eigen filmcultuur, dát is de les die Buffalo Bill's paradefilms ons na een eeuw voorhoudt.

\section{Noten}

I Deze film en andere hier besproken films liggen in het archief van de Library of Congress in Washington DC. De meeste van de hier genoemde titels zijn op de website van de Library of Congress te bekijken. (URL: http://www.lcweb.loc. $\mathrm{gov} / \mathrm{rr} / \mathrm{mopic} /)$.

2 De officiële naam van Buffalo Bill's show was Buffalo Bill's Wild West and Congress of Rough Riders. Nadat in 1898 Theodore Roosevelt zijn manschappen tijdens de Spaans-Amerikaanse oorlog de Rough Riders noemde, vernoemd naar de figuren in de wildwest show, eerde Buffalo Bill Roosevelt en zijn mannen op zijn beurt door een reconstructie van de slag van San Juan Hill in zijn show op te nemen. Zie voor een beschrijving van de cast van Buffalo Bill's wildwest shows Richard Slotkin, Gunfighter Nation: The Myth of the Frontier in 2oth-Century America, New York 1992, en Don Russell, The Lives and Legends of Buffalo Bill, Norman 1960.

3 In KINtop. Jahrbuch zur Erforschung des frühen Films, 6 (1997) staat de vroege actualiteitsfilm centraal. In de inleiding wordt een beschrijving van dit eerste genre van korte non-fictiefilms gegeven: 'Krönungen, Paraden, Staatsbesuche, Umzüge, Einweihungsfeiern, Denkmalsenthüllungen und dergleichen mehr: Gerade in den Anfangsjahren der Kinematographie machen Ereignisse des öffentlichen Lebens einen bedeutenden Teil der Filmproduktion aus. Vor Ort gedreht oder nachgestellt - Aktualitätenfilme gestatten dem Zuschauer, sich 'ein Bild zu machen' von Ereignissen, von denen er schriftlich aus der Presse oder einfach nur mündlich vom Hörensagen erfahren hat' (p. 7). Zoals hier wordt uitgelegd, wordt de diversiteit van deze films duidelijk door de verschillende betekenissen van de term 'actualiteit' in verschillende talen. Zo wordt de Franse term actualitégebruikt voor iedere film die gaat over actuele gebeurtenissen die interessant zijn voor het grote publiek. De Engelse benaming topical film benadert deze betekenis nog het sterkst. Actuality betekent meer in het alge- 
meen de werkelijkheid. In de filmgeschiedschrijving wordt deze term echter gebruikt om de non-fictie film uit de eerste decennia van het medium aan te duiden, ter onderscheiding van de documentary die pas gedateerd kan worden nadat Grierson de term lanceert en definieert. Zie voor een beschrijving van de verschillende termen de bijdragen van William Uricchio en Sabine Lenk in KINtop, 6.

4 Charles Musser, 'Respektabilität und Aktualität: Gedanken zum kulturellen Stellenwert von Edisons Filmen in der Kinetokop-Ära', in: KINtop, 6, 1997 , p. 77.

5 Zie William Uricchio, 'Aktualitäten als Bilder der Zeit', in: KINtop, 6, 1997, p. 43-50, en 'Cinema als omweg. Een nieuwe kijk op de geschiedenis van het bewegend beeld', in: Skrien, 199, 1994, p. 54-57.

6 Musser benadrukt de inspiratie die Edison voor zijn uitvinding opdeed bij de experimenten van Muybridge die met zijn zoöpraxiscope beweging fotografisch ontleedde. Zij spraken in 1888 over de mogelijkheden om de uitvinding van de fonograaf geschikt te maken voor de opname van bewegend beeld. Musser citeert Edison: 'I am experimenting upon an instrument which does for the Eye what the phonograph does for the Ear, which is the recording and reproduction of things in motion, and in such form as to be both cheap, practical, and convenient.' Zie Charles Musser, Before the Nickelodeon: Edwin S. Porter and the Edison Manufacturing Company, Berkeley 1991, p. 129.

7 In The Real Thing: Imitation and Authenticity in American Culture, Chapel Hill/Londen 1989, geeft Miles Orvell een mooie analyse van de verschuiving van een negentiende-eeuwse cultuur van imitatie naar een twintigste-eeuwse cultuur van authenticiteit in de kunsten en media. Filmhistorici die de wijze bestuderen waarop film zich rond de eeuwwisseling tot deze aspecten van het bredere culturele discours van moderniteit verhoudt, zijn bijvoorbeeld Tom Gunning, Vanessa Schwartz, en William Uricchio. Zie ook de bundels: Daan Hertogs \& Nico de Klerk (red.), Uncharted Territory: Essays on Early Nonfiction Film, Amsterdam 1997, en Leo Charney \& Vanessa R. Schwarz (red.), Cinema and the Invention of Modern Life, Berkeley 1995.

8 De gebroeders Lumière namen bijvoorbeeld in 1895 hun eerste film op, sORTIE D'USINE, waarin zij de arbeiders van de Lumière-fabriek registreerden. Edisons werknemers traden in enkele vroege films ook zelf op als acteurs, zoals in BLACKSMITH SCENE (1893) EN EDISON KINETOSCOPIC RECORD OF A SNEEZE (I894).

9 De kinetoscoop, gepatenteerd in $189 \mathrm{I}$, bestond uit een kast waarin één persoon een film kon bekijken door een kijkgat. De mogelijkheid om film in projectie te vertonen aan een groter publiek was vóór 1895 nog niet ontwikkeld. De kijkkasten werden in zogeheten Kinetoscope Parlours opgesteld waar publiek door vijf cent in de gleuf van het apparaat te steken een kort filmpje kon bekijken. Zie voor een uitgebreide beschrijving van deze periode: Musser, Before the Nickelodeon, p. 29-56.

Io Interessant is het feit dat Buffalo Bill vanaf 1893 meer dan daarvoor een claim van realisme van zijn shows benadrukte. Zie Slotkin, Gunfighter Nation, p. $8 \mathrm{I}-82$. Hoewel Slotkin niet expliciet een relatie legt met het begin van de film, is de coïncidentie frappant. 
II Voor een bespreking van de verschillende uitingsvormen van, en condities voor, nostalgie, zie Malcolm Chase en Christopher Shaw's artikel 'The Dimensions of Nostalgia' in: Shaw \& Chase (red.), The Imagined Past: History and Nostalgia, Manchester/New York 1989, p. I-17. David Lowenthal traceert in 'Nostalgia Tells it Like it Wasn't' in dezelfde bundel de verschuivende betekenis van de term vanaf de zeventiende eeuw - als term uit de medische wereld -, tot de moderne, metaforische betekenis in de twintigste eeuw. Hierbij belicht hij met name de moderne vorm van nostalgie, die gebaseerd is op een zeer korte tijd tussen een gebeurtenis en het nostalgische verwerken van deze tijd: 'As obsolescense conferred instant bygone status, history was being recycled as nostalgia almost as soon as it happened.' Zie verder ook zijn boek The Past is a Foreign Country, Cambridge 1995.

I2 Alison Griffiths, 'Playing at Being "Indian": Ethnographic Realism in the Early Western', te verschijnen in William Uricchio en Nanna Verhoeff (red.), Blurred Vistas: The Western Film Before I9IS, in voorbereiding.

I3 Zoals in 'The Wild West', The New York Tribune, I juli 1894, p. 14, en in 'Day With the Wild West', 22 juli 1894 , p. I5. Zie Musser, Before the Nickelodeon, p. 500 .

I4 De films die Edisons cameramannen in dit jaar met de kinetograaf opnamen konden in de kinetoscoop bekeken worden. Een aantal van deze films is te bekijken op de internet-site van de Library of Congress: Inventing Entertainment: The Motion Pictures and Sound Recordings of the Edison Companies (URL:http://lcweb2.loc.gov/ammem/edhtml/edhome.html).

is Edison Films Catalog, ros, juli 1901, p. 49. Zie de catalogus op de internetsite van de Library of Congress.

16 Musser, Before the Nickelodeon, p. so.

17 Voorbeelden van parade films, al dan niet met western-figuren, zijn: PRESIDENT ROOSEVELT AND THE ROUGH RIDERS (AM\&B, I898), BUFFALO POLICE ON PARADE (Edison, 1897), NATIVE DAUGHTERS (Edison, 1898), PROCESSION OF MOUNTED INDIANS AND COWBOYS (Edison, I898), CONVENTION OF THE RED MEN (Edison, ca. 1904), en PARADE OF CHINESE (Edison, I898).

I8 Gaudealt en Gunning introduceerden de term in 1985 in hun lezing op het congres 'Nouvelles approches de l'histoire du Cinéma' in Cerisy. Gunning werkte dit begrip uit in 'The Cinema of Attractions: Early Film, Its Spectator and the Avant-Garde', in: Wide Angle, 8, 3/4, 1986, p. 63-70.

19 Gunning, 'Before Documentary: Early Nonfiction Films and the "View" Aesthetic', in: Hertogs \& de Klerk (red.), Uncharted Territory.

20 Voor een bespreking van de betekenis van toerisme voor de verbeelding van landschap in de travelogues, of: reisfilms, in de jaren 'Io, zie Jennifer Peterson's artikel "Truth is Stranger Than Fiction": Travelogues from the rios in the Nederlands Filmmuseum', in: Hertogs en de Klerk (red.) Uncharted Territory, p. 75-90. Uricchio verbindt de documentaire betekenis van het landschap en de positie van het mimetische in de vroege fictionele western met de esthetiek van het picturesque, in: 'Grensgebieden: feit, fictie en het picturesque in de vroege western', in: Tijdschrift voor Literatuurwetenschap, 3, 1998, 2, p. 99-109.

2I Voorbeelden zijn terRIBle TEDdy, THE GRIZZLY KING (Edison, 1901), CRIPPLE CREEK BAR-ROOM SCENE (EdisON, I899), POKER AT DAWSON CITY 
(Edison, 1899); A WESTERN STAGECOACH HOLD UP (Edison, 1904), en A FRONTIER FLIRTATION (AM\&B, 1903).

22 Voor een toepassing van het begrip bricolage van Lévi-Strauss op de vroege film, zie Richard Abel, The Ciné Goes to Town: French Cinema 1896-1914, Berkeley 1998; Miriam Hansen, Babel \& Babylon: Spectatorship in American Silent Film, Cambridge, Massachusetts 1991; Alan Williams, Republic of Images: A History of French Filmmaking, Cambridge, Massachusetts 1992.

23 Hansen, Babel \& Babylon, p. 47-48.

24 Variety, 19 januari 1907, p. 9.

25 Deze tekst is te lang om hier weer te geven; hij moet in z'n geheel gelezen worden om de samenhang van de scènes te kunnen onderscheiden. Beide documenten zijn herdrukt in Musser, Before the Nickelodeon, p. 360-361.

26 Hansen, Babel \& Babylon, p. 47-48.

27 Kevin Brownlow, The War, The West, and the Wilderness, New York 1979, p. 223.

28 Moving Picture News, 18 november 19II, p. 6.

29 Moving Picture News, 27 april 1912, p. 4.

30 Slotkin, Gunfighter Nation, p. 87. 